\title{
LEPTIN DIRECTLY STIMULATES PARATHYROID HORMONE SECRETION
}

lgnacio Lopez ${ }^{1,2}$, Carmen Pineda ${ }^{1,2}$, Ana Raya $^{1,2}$, María E Rodríguez-Ortiz², Juan M Díaz-

Tocados $^{2}$, Rafael Ríos ${ }^{1,2}$, Mariano Rodriguez ${ }^{2}$, Escolastico Aguilera ${ }^{1,2}$ and Yolanda Almadén².

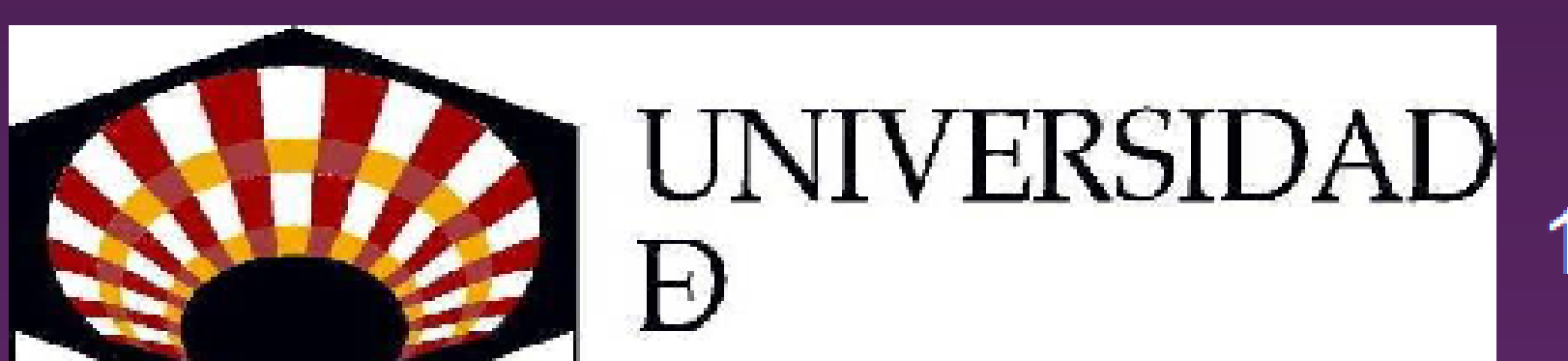
$\mathrm{E}$
CORDOBA

1 Dept. Animnal Medicine and Surgery, Veterinary School, University of Cordoba, Spain. IMIBIC ${ }^{2}$ Research Unit, Nephrology Service, Hospital Reina Sofia, IMIBIC, Cordoba, Spain.

\section{INTRODUCTION}

- Leptin is an adipokine secreted by fat tissue which plays a major role in energy metabolism.

- Leptin is best known for its modulatory effects on food intake: by acting on the central nervous system leptin inhibits appetite.

- A relationship between obesity, plasma leptin concentration and primary hyperparathyroidism has been previously reported.

\section{OBJECTIVE}

The aim of this study was to test the hypothesis that leptin directly stimulates PTH secretion by the parathyroid glands.

\section{MATERIALS AND METHODS}

\section{In vivo studies}

\section{Animal Model}

-Two strains of rats were used in the in vivo studies: lean ( $\mathrm{Fa} / \mathrm{Fa}, \mathrm{Fa} / \mathrm{fa})$ Zucker rats $(n=15)$ and obese (fa/fa) Zucker rats $(n=9)$. The fa/fa Zucker rats are natural mutants that do not express active leptin receptors and therefore are non sensitive to leptin.

\section{Experimental Design}

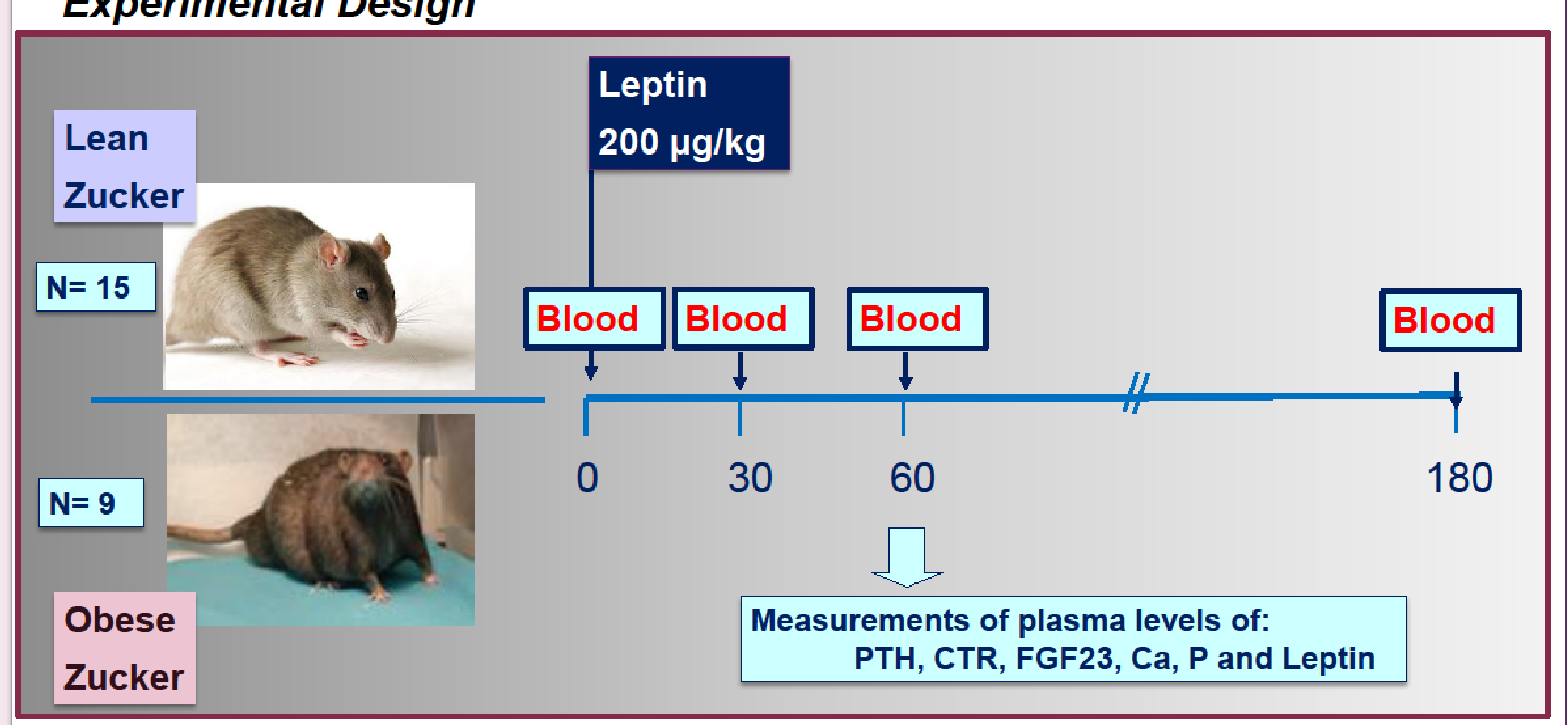

\section{In vitro studies}

- Rat parathyroid glands were obtained as previously described (Almaden et al. 1996) from male Wistar rats ( $250 \mathrm{~g}$ body $\mathrm{wt})$.

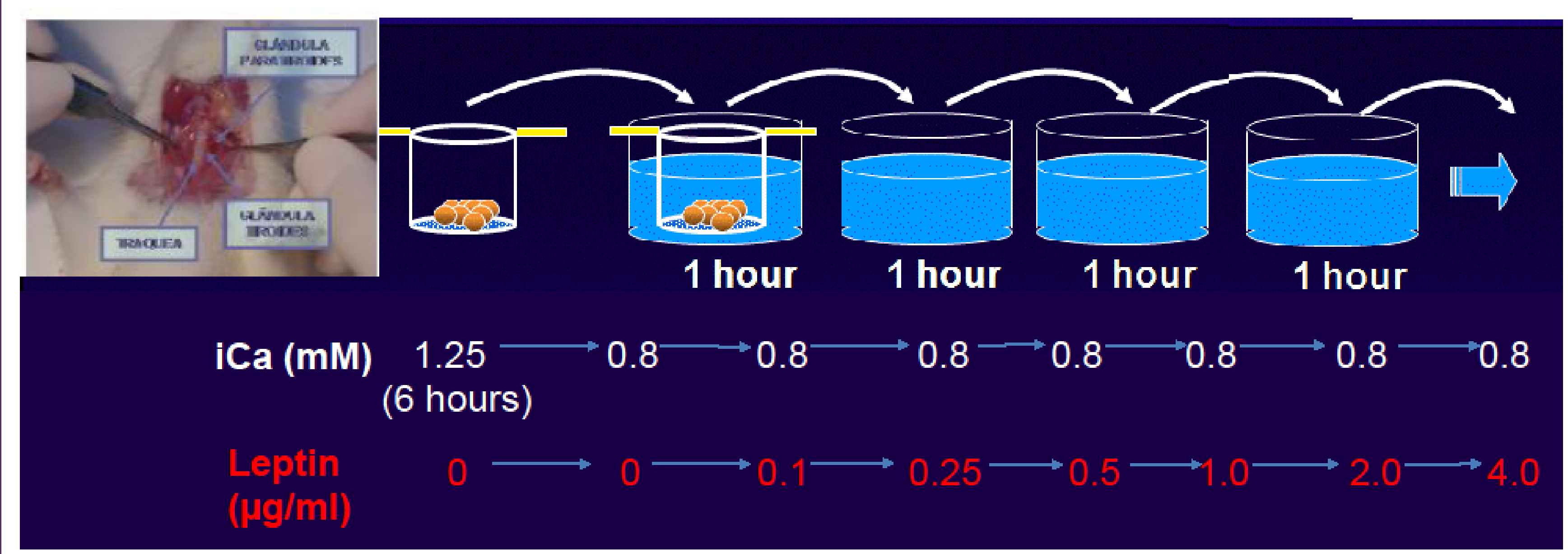

Measurements

- Blood for measurement of iCa was performed by selective electrode (Ciba-Corning 634 ISE Ca2+/pH Analyzer, Essex, England).

- Plasma levels of PTH were quantified using a rat bioactive intact PTH ELISA kit (Immunotopics, San Clemente, CA, USA).

- Plasma $\mathbf{P}$ was measured by spectrophotometry (BioSystems SA, Barcelona, Spain).

- Radioimmunoassay was used in plasma samples to determine leptin (Millipore, St. Charles, MO, USA) and 1,25(OH)2-vitamin D3 (IDS kit, Boldon, UK).

- Plasma FGF23 levels were determined using a rat FGF23 ELISA Kit (Kainos laboratories Inc., Tokyo, Japan).

\section{RESULTS}

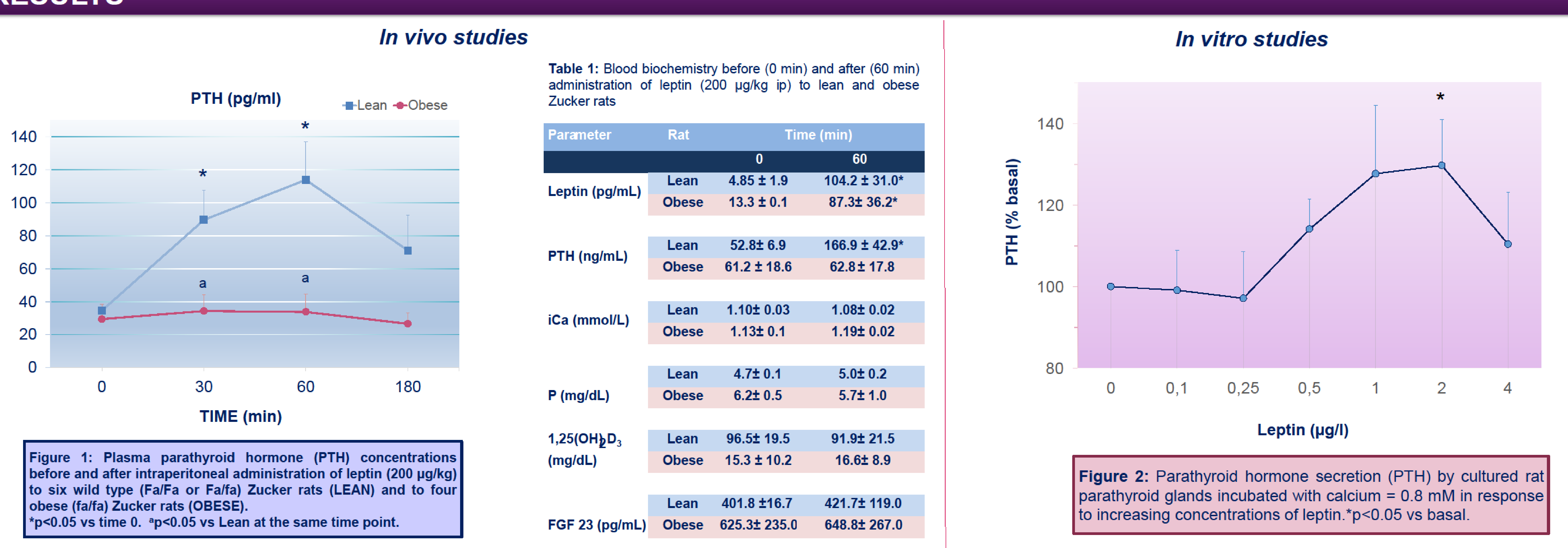

\section{CONCLUSION}

The results of the present study demonstrate a direct stimulatory effect of leptin on PTH secretion and suggest the existence of an endocrine axis between fat tissue, where leptin is mainly produced, and the parathyroid glands.

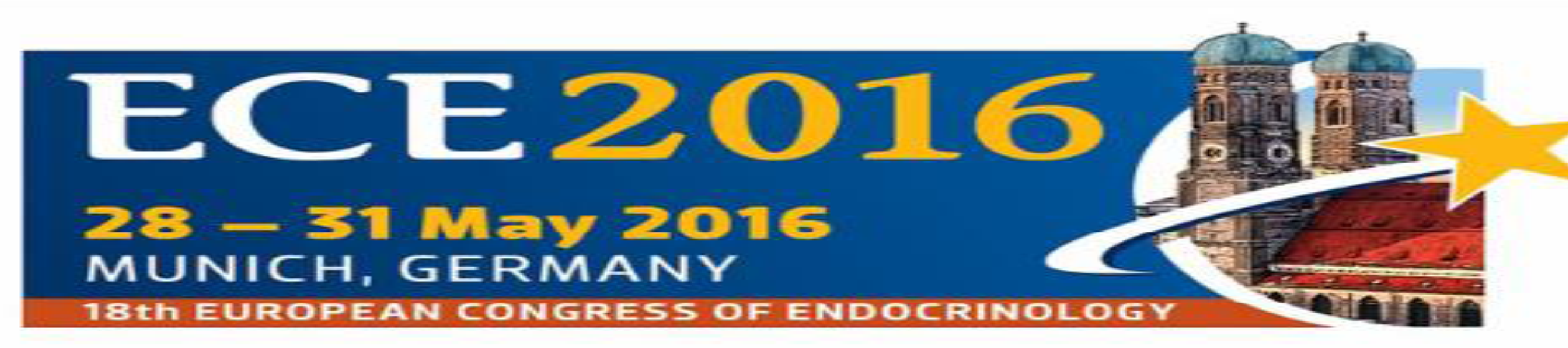

